\title{
АНАЛИЗ ИНФОРМАЦИИ О ВНЕДРЕНИИ ИНСТРУМЕНТОВ БЕРЕЖЛИВОГО ПРОИЗВОДСТВА И ИХ ВЛИЯНИИ НА ЭФФЕКТИВНОСТЬ КОМПАНИИ
}

\section{ANALYSIS OF INFORMATION \\ ON THE IMPLEMENTATION OF LEAN PRODUCTION TOOLS AND THEIR INFLUENCE ON THE EFFICIENCY OF THE COMPANY}

\section{E. Romanova}

Summary: The paper presents the results of the analysis of open information over the past 5 years about the most effective tools of lean production, introduced at Russian enterprises in the production and non-production areas. The influence of the problems solved by lean manufacturing tools on the efficiency of educational organizations is demonstrated.

Keywords: lean manufacturing, production system, information analysis.

\author{
Романова Елена Юрьевна \\ К.п.н., Российский государственный \\ социальный университет \\ clenar2001@mail.ru
}

Аннотация: В работе проведены результаты анализа открытой информации за последние 5 лет 0 наиболее эффективных инструментах бережливого производства, внедренных на российских предприятиях в производственной и непроизводственных сферах. Продемонстрировано влияние проблем, решаемых инструментами бережливого производства на эффективность образовательных организаций.

Ключевые слова: бережливое производство, производственная система, анализ информации.

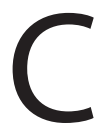

истема «Бережливое производство» - это подход к управлению организацией, основанный на повышении качества продукции при одновременном сокращении расходов.

Концепцию бережливого производства разработал инженер и предприниматель компании Тойота Тайити Оно вместе со своим соратником Сигео Синго. В дальнейшем она была адаптирована под американские компании и названа Lean Production [1]. В [2] подчеркивается, что методика встраивания культуры бережливого производства в организационную структуру предприятия согласовано с основной производственной стратегией.

Главная задача бережливого производства состоит в непрерывном устранении потерь, добиваясь снижения стоимости продукта и повышения качества. Тайити Оно предложил семь видов потерь, потом американские исследователи управления к ним добавили еще три.

В последнее время вышло несколько значительных обзоров публкаций. В [3] сделан систематический обзор литературы журнальных статей издательств Emerald Online, Science Direct, Springer Link и Taylor \& Francis c группировкой по тематическим направлениям внедрения бережливого производства. В обзоре [4] можно найти работы по таким темам, как: проблемы при внедрении, стандарты и лучшие практики внедрения, оценки эффективности внедрения в промышленности, и интеграция бережливого производства с другими производственными системами.

В России с 2014 года началась разработка, публикация и утверждение серии стандартов, раскрывающих модель системы менеджмента бережливого производства: основные положения и словарь(ГОСТ Р 560202014); требования к системам менеджмента(ГОСТ Р 56404-2015); процесс сертификации систем менеджмента. процедура оценки(ГОСТ Р 56405-2015); аудит. вопросы для оценки системы менеджмента(ГОСТ Р 56406-2015); основные методы и инструменты(ГОСТ Р 56407-2015); организация рабочего пространства (5S) (ГОСТ Р 569062016); визуализация(ГОСТ Р 56907-2016); стандартизация работы(ГОСТ Р 56908-2016); руководство по системе подготовки персонала(ГОСТ Р 57523-2017); поток создания ценности(ГОСТ Р 57524-2017); руководство по интегрированной системе(ГОСТ Р 57522-2017); особые требования по применению бережливого производства в судостроительной промышленности (с 01.01.2021, ГОСТ Р 58589-2019).

В 2018 году президиумом Совета при Президенте Российской Федерации по стратегическому развитию и приоритетным проектам утвержден Паспорт национального проекта «Производительность труда и поддержка занятости». Национальный проект предполагает системное совершенствование существующей экономи- 
ческой базы страны, и внедрение методов бережливого производства на предприятиях позиционируется как одно из важнейших мероприятий, в которое вовлечены десятки крупных и средних предприятий.

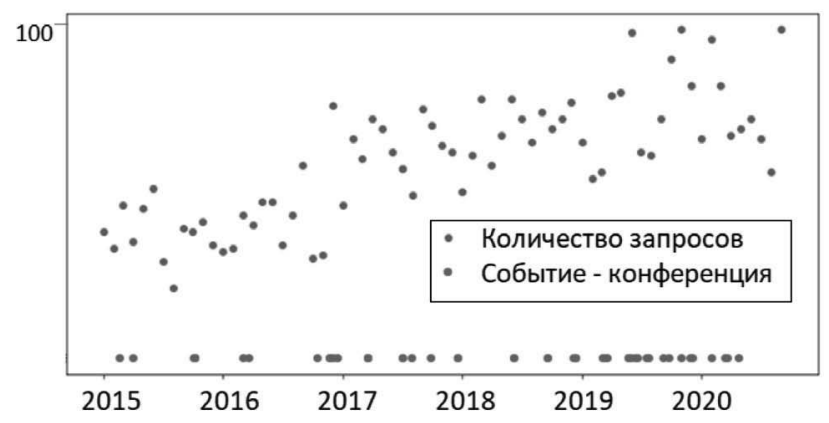

Рис. 1. Диаграмма популярности тематики

Данные о количестве запросов к системе Goodle. Trends по терминам бережливого производства и количество проведенных конференций (Рис.1) демонстрируют интерес к обмену опытом и методам бережливого производства.

В данной работе проведено исследование практик внедрения модели бережливого производства за последние 5 лет на основании изучения информации из открытых источников и сайтов 44 компаний, относящихся как к производственной, так и непроизводственной сферам, таких, как ПАО НЛМК, Камаз, АО ОАК, АО «AMC», ПАО «Компания Сухой», НАЗ им. В.П. Чкалова, Банк ВТБ, «СИБУР Холдинг», компания «ХОМА», «Камский кабель», «Трансмашхолдинг», «Первая грузовая компания», «Росатом», «Базовый Элемент», АО «ОСК», АО «Концерн ВКО «Алмаз-Антей», «ГОЗ Обуховский завод», АК ОЗНА, Башкирской генерирующая компания, АО «Интер РАО - Электрогенерация», Красноярская магистраль, Сбербанк, Банк ВТБ, «Базэл Аэро» (промышленная группа «Базовый Элемент»), всего по категориям: серийное производство - 14, штучное производство - 7, офис - 2, банк - 6, образование - 9, услуги (транспорт) - 6 .

Автором статьи проведена обработка выступлений представителей компаний на конференциях. Наиболее эффективные методы бережливого производства представлены в Таблице 1 по частоте встречаемости в докладах.

Как правило, производственная система предприятия включает в себя большое число этих инструментов и методик бережливого производства, а конкретный состав применяемых инструментов зависит от условий и задач. При этом применяется системный подход: анализ производственных процессов с позиций формирования ценности приводит к декомпозиции целей и выстраиванию системы бережливого производства.
Таблица 1.

Частота внедрений инструментов бережливого производства (по материалам конференций)

\begin{tabular}{|l|c|}
\multicolumn{1}{|c|}{ Инструмент бережливого производства } & $\begin{array}{c}\text { Частота внедрений, } \\
\%\end{array}$ \\
\hline обучение руководства и персонала & 87 \\
\hline $\begin{array}{l}\text { создание рабочей группы по внедрению и 0б- } \\
\text { суждению предложений }\end{array}$ & 82 \\
\hline внедрение системы «5ऽ» & 69 \\
\hline $\begin{array}{l}\text { сбора и реализации предложений } \\
\text { по улучшениям }\end{array}$ & 60 \\
\hline стандартизация & 37 \\
\hline реализации «Биржи идей» & 32 \\
\hline организация кайдзен-менеджмента & 19 \\
\hline $\begin{array}{l}\text { картирование потока создания ценности и ви- } \\
\text { зуализация логистических процессов }\end{array}$ & 16 \\
\hline выравнивание потоков & 14 \\
\hline система вытягивания & 14 \\
\hline балансировка линий & 14 \\
\hline всеобщее обслуживание оборудования & 12 \\
\hline канбан & 12 \\
\hline быстрая переналадка оборудования & 10 \\
\hline $\begin{array}{l}\text { определение пилотных участков } \\
\text { «талонная линия» }\end{array}$ & 7 \\
\hline андон & 7 \\
\hline сотовая планировка & 7 \\
\hline $\begin{array}{l}\text { тиражирование бригадной формы организа- } \\
\text { ции труда. }\end{array}$ & \\
\hline обучение руководства и персонала & \\
\hline
\end{tabular}

Для серийных, массовых производств характерно, что устранение потерь происходит на операционном уровне.

В производственных организациях с единичной и мелкосерийной загрузкой также отмечаются значительные успехи от внедрения моделей бережливого производства. Однако специфика производства смещает оптимизацию на обеспечивающие работы. Так, в [5] отмечается, что АО «ОСК» может влиять только на $40 \%$ формирования стоимости изделия, контроля затрат, качества выполняемых работ, при сокращении времени материальной обработки (значимой для ценности продукта работы) изделия на 200\% время исполнения всего процесса уменьшится на 7,5\% в силу невозможности и дороговизны изменения технологии, тогда как уменьшение времени обеспечивающих работ на $40 \%$ сократит время процесса на $34 \%$.

Эффективность внедрения для некоторых компаний представлена в Таблице 2 (данные собраны автором). 
Таблица 2.

Эффективность внедрения бережливого производства

\begin{tabular}{|l|c|c|}
\multicolumn{1}{|c|}{ Компания } & $\begin{array}{c}\text { Реализовано } \\
\text { проектов, идей }\end{array}$ & $\begin{array}{c}\text { Доход от внедрения } \\
\text { (млн. руб.) }\end{array}$ \\
\hline ТМК & 98 & 571 \\
\hline РНПК & 15 & 2400 \\
\hline «Базовый Элемент» & 70 & 300 \\
\hline ЧТПЗ & 1500 & 400 \\
\hline АО «ОСК» & 694 & 5800 \\
\hline МТС & 200 & 264 \\
\hline ПАО Компания Сухой & 930 & 40 \\
\hline «Газпром переработка» & 40 & 600 \\
\hline АО ОАК & 20 & 220 \\
\hline ГК «ЛокоТех» & 217 & 9,7 \\
\hline Сбербанк & 4000 & 4300 \\
\hline ММК & 3872 & 453,6 \\
\hline «АгроХолдинг «Кубань» & 500 & 122 \\
\hline
\end{tabular}

Мировой тенденцией является перенос методик бережливого производства в цифровую среду в связи с цифровизацией экономики. Так, в области строительства, как отмечается в [6], на практике и в исследованиях существует множество подходов, поддерживающих планирование и контроль производства, которые, однако, сосредоточены на отдельных областях, таких как контроль затрат или стабилизация рабочего процесса . Информационное моделирование зданий (BIM) в качестве подхода к цифровому моделированию в строительной отрасли может помочь стандартизировать управление производством за счет смещения дизайна системы управления в сторону цифрового прототипа. Опыт российских компаний («Мосстрой 11») подтверждают этот подход, позиционируя ВІМ как неотъемлемую часть систем управления производством.

Важнейшим фактором развития практически все руководители компаний отмечают вовлеченность персонала. «На старте шла речь о повышении эффрективности процессов департамента операционной поддержки бизнеса с применением инструментов lean. - говорит Елена Туманова, советник департамента операционной поддержки бизнеса банка ВТБ по внедрению производственной системы на базе Lean-технологий. - Однако мы очень быстро поняли, что инструменты без формирования внутренней бережливой культуры не дадут нужного эфффекта» [7].

Продвижение идеи бережливого производства в непроизводственный, в частности, в образовательный сектор, ориентировано на менеджмент по устранение потерь и постоянное совершенствование деятельности и процессов, а не на конвейерное, производственное мышление. Такой подход означает, что все первичные и второстепенные виды деятельности, начиная с организации приемной компании, зачисления, преподавания и сопровождения учебного процесса, включая деятельность в цифровой среде, организационные структуры, должны быть проанализированы с точки зрения потерь и деятельности с добавленной стоимостью. На основании этой оценки процессы могут быть пересмотрены и оптимизированы по разрабатываемым критериям эффективности образовательных организаций.

Практики бережливого производства включают сотрудников каждого отдела и каждый уровень, проводится документирование текущей практики, определение возможностей для улучшения, внедряются позитивные изменения в каждый процесс, который способствует реализации образовательного процесса. Проведенный опрос ППС и сотрудников 6 вузов с использованием методики [8] показал, что из инструментов бережливого производства существенный вклад в оптимизацию вносят «5S» и «Биржа идей».

Приведем пример анализа, показывающей, что реализация идей бережливого производства будет способствовать повышению эффективности образовательной организации.

Для этого рассмотрим показатели эффективности образовательных учреждений высшего образования, подведомственных Министерству науки и высшего образования Российской Федерации, утвержденных Приказом N 475 от 24.03.2020 и выберем один из них - средний балл за ЕГЭ зачисленных на бюджет студентов (далее - средний балл). В работе используются данные по вузам г. Москвы за 2019, приведенные на сайте [9] как результат мониторинга каче-

\section{перепроизводство}

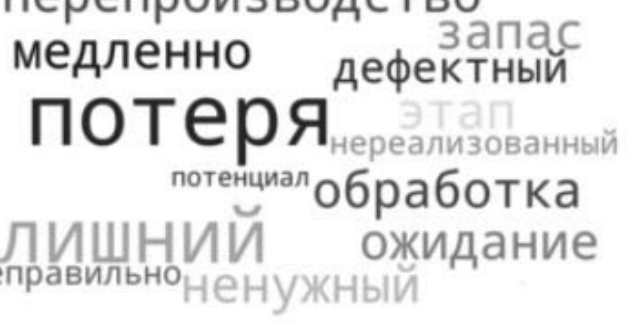

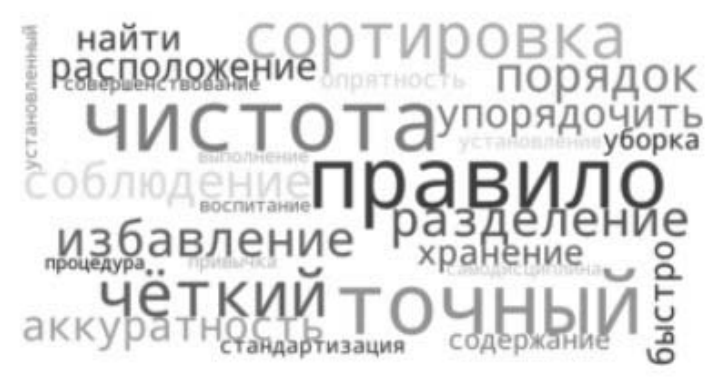

Рис. 2. Облака слов для описания: потерь (слева) и «5S» (справа) 
ства приема в вузы, осуществленного НИУ ВШЭ.

На формирование данного показателя влияет репутационный фактор, формируемый, в частности под действием общественного мнения.

Репутационный фактор можно оценить по отзывам, оставляемым на открытых площадках. К сожалению, такая оценка сильно зашумлена современными тенденциями «накрутки отзывов», что необходимо учитывать.

Для исследования было собрано из открытых источников (интернет) база отзывов и проставленные авторами репутационные баллы вузов. Средние значения репутаций вузов монотонно повышаются с увеличением диапазона среднего балла (менее 67: 4,18; от 67 до 72: 4,21; выше 73: 4,31). Проводился анализ сходства текстов отзывов и описаний потерь согласно концепции бережливого производства и описания концепции «5S» (см. Рис.2).

В качестве меры сходства использовалась косинусная мера, в качестве эмбеддингов - вектора размерности 100 с сайта [10] тезауруса русского языка. Результаты анализа представлены ниже.

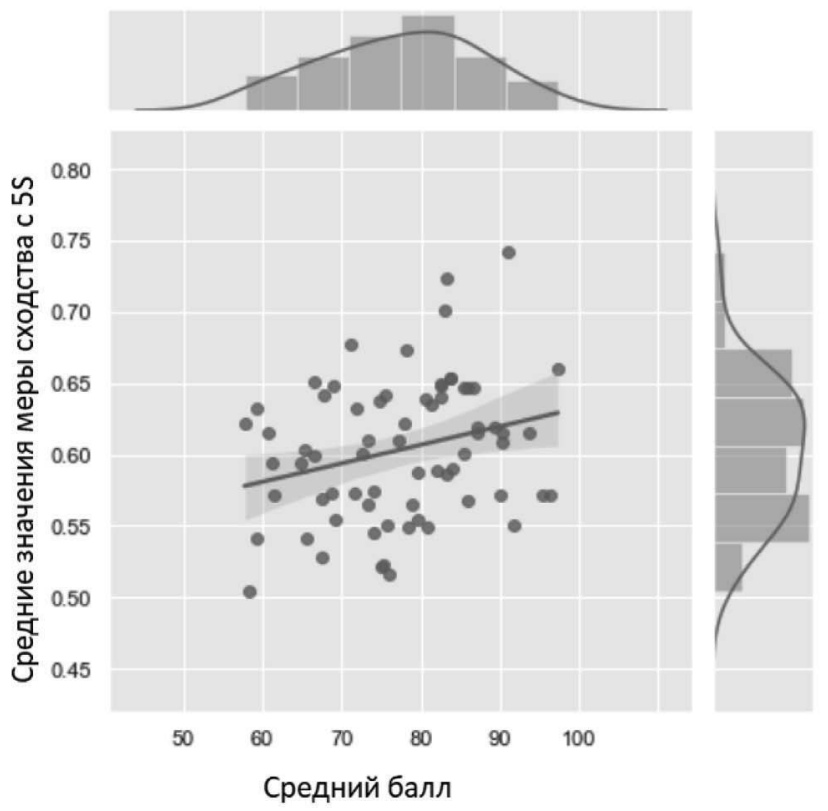

Рис. 3. Сходство текстов отзывов и описания «5S» в зависимости от среднего балла

На Рис. 3 представлены распределения значений средних баллов и средних значений для каждого вуза мер сходства текстов отзывов с основными идеями «5S». Эти величины слабо коррелируют, коэффициент детерминации 0,31. Отзывы по вузам с высокими баллами содержат больше фраз о быстроте обслуживания в приемной комиссии, быстроте получения информации, оперативности, чистоте, красивом внешнем виде и удобстве расположения -значит, можно предположить, что реализация концепции «5S» будет вызывать положительные эмоции у потенциальных абитуриентов и способствовать повышению рейтинга вуза.

На Рис. 4 изображены диаграммы распределения средних значений для каждого вуза мер сходства текстов отзывов с описанием потерь согласно концепции бережливого производства. Так как описание потерь носит негативный оттенок, чем меньше значение на диаграмме, тем лучше. Видно, что слов, близких по смыслу к описанию потерь (см. Рис 2, слева)) в вузах с выставляемой оценкой «5» меньше, чем у вузов с оценками «4» или с оценками «3» (значимо на уровне 5\%). У вузов с оценками «1» претензий по «потерям» также меньше по сравнению с вузами с оценкой «3» или «4», видимо, смыслы претензий лежат в других плоскостях.

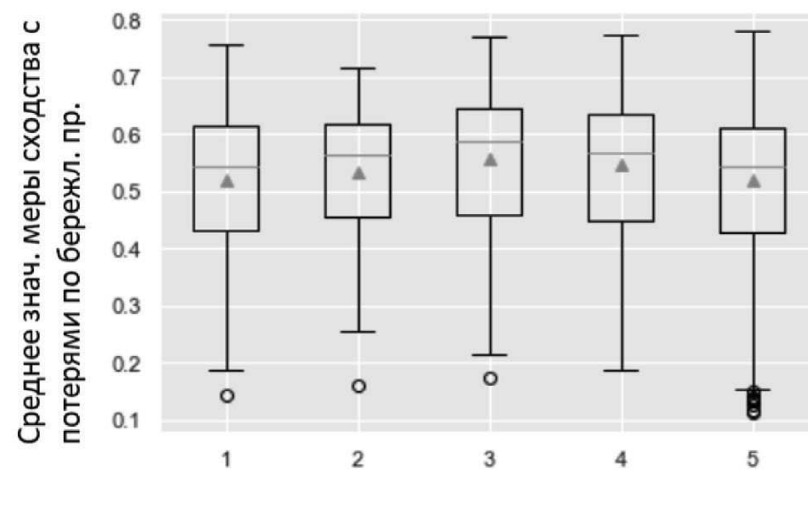

Оценка вузу, выставленная автором отзыва

Рис. 4. Сходство текстов отзывов и описания потерь в зависимости от среднего балла

Таким образом, проблемы абитуриентов, созвучные описанию потерь, приводят к появлению в открытых источниках (интернете) отзывов с пониженными оценками, что в итоге влияет на общественный рейтинг вуза.

Итак, в статье отражены результаты исследования наиболее успешных практик и инструментов бережливого производства, внедренных как на предприятиях производственной и непроизводственной сфер. Особую важность имеет обучение ведущих менеджеров системе бережливого производства и вовлеченность всего персонала. Обучение руководящего состава способствует выстраиванию организационных процессов в соответствие с системой бережливого производства.

Для образовательных организаций выявлена репутационная важность реализации принципов $5 \mathrm{~S}$ и бережливого производства.

Работа выполнена по внутреннему НИР РГСУ «Оценка эффективности проведенных мероприятий по оптимизации и улучшению условий труда преподавателей, административного персонала и обучающихся», Приказ № 567. 


\section{ЛИТЕРАТУРА}

1. Вумек Джеймс П., Джонс Даниел Т., Рус Дэниел. Машина, которая изменила мир. // М.: Попурри, 2007.

2. Marc Helmold. Lean Management and Kaizen. Fundamentals from Cases and Examples in Operations and Supply Chain Management // Springer International Publishing. 2020. D0I: 10.1007/978-3-030-46981-8

3. Psomas, Evangelos \& Antony, Jiju. Research gaps in Lean manufacturing: a systematic literature review. // International Journal of Quality \& Reliability Management. 2019, v. 36. D0I: 10.1108/IJQRM-12-2017-0260.

4. de Oliveira, R.I., Sousa, S.0. \& de Campos, F.C. Lean manufacturing implementation: bibliometric analysis 2007-2018. // The International Journal of Advanced Manufacturing Technology, v. 101, p. 979-988, 2019. D01: 10.1007/s00170-018-2965-y

5. Чуй С.А. Особенности внедрения бережливого производства. Переход к развитию производственной системы судостроения // онлайн: https:// soyuzmash.ru/docs/prez/prez-kspmt-270516-1.pdf

6. Белостоцкая Н. Бережливый банк: путь к производственной системе // онлайн: https://kachestvo.pro/kachestvo-upravleniya/svoy-put/berezhlivyy-bankput-k-proizvodstvennoy-sisteme/)

7. Schimanski, C.P., Pasetti Monizza, G., Marcher, C. et al. Development of a BIM-based production planning and control system for Lean Construction through advancement and integration of existing management techniques. // Frontiers of Engineering Management, v. 4, 2020. D01: 10.1007/s42524-020-0105-5

8. Блохина 0.А., Подзорова М.И., Романова Е.Ю. Применение моделей IRT в IT-консалтинге // В сборнике: Экономическое прогнозирование: модели и методы. материалы ХІІ международной научно-практической конференции. 2016. С. 8-11.

9. Сайт https://ege.hse.ru/

10. Сайт https://nlpub.ru

(c) Романова Елена Юрьевна (lenar2001@mail.ru).

Журнал «Современная наука: актуальные проблемы теории и практики»

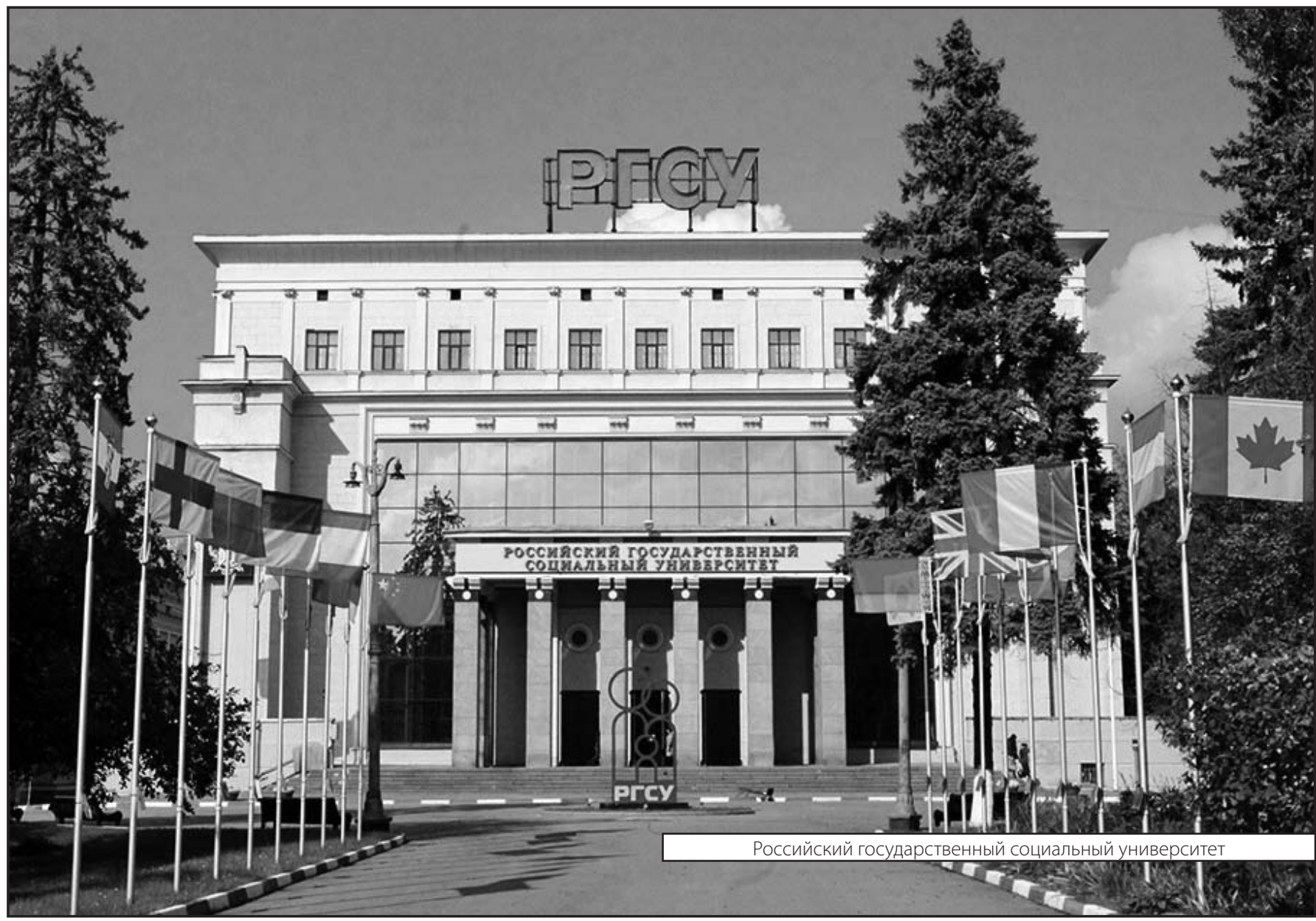

